\title{
A New Approach for the Design, Construction and Control of Compacted Mineral Liners of a MSW Landfill Capping
}

\author{
G. Cortellazzo ${ }^{1} \cdot$ M. C. Mandaglio ${ }^{2} \cdot$ S. Busana ${ }^{3} \cdot$ M. Favaretti $^{1} \cdot$ N. Moraci $^{4}$ (D)
}

Received: 15 June 2020 / Accepted: 6 October 2020 / Published online: 19 October 2020

(c) The Author(s) 2020

\begin{abstract}
Design parameters typically used for the mineral liner of landfill cover system (e.g. water content $w$, dry density $\rho_{\mathrm{d}}$ and hydraulic conductivity $k$ ) are often difficult to obtain on site. After construction, these experimental parameters need to be checked against the predicted values. In this paper, a rigorous procedure for design, construction and control of a compacted mineral liner in a capping multilayer system has been developed. The procedure has been schematically subdivided in three phases. The first phase (design) was based on a wide preliminary set of laboratory tests, composed of classification, compaction and permeability tests. An analytical relationship among degree of saturation $S_{\mathrm{r}}$, dry density $\rho_{\mathrm{d}}$ and hydraulic conductivity $k$ is also defined. The second phase (construction) was developed through a suitable compaction of the mineral liner planned after the design phase. The last phase (in-site control) consists of checking the design parameters $\left(w, S_{\mathrm{r}}, \rho_{\mathrm{d}}, k\right)$ actually achieved on site. A comparison between coefficients $k$, obtained through site permeability tests and an analytical relationship obtained in the design phase, was made successfully. Owing to this new approach, it will no longer be necessary to perform in situ permeability tests, but it will be enough to define the above-mentioned analytical relationship during the design phase. In this way, a dangerous damage to the mineral liner, caused by the execution of invasive permeability tests, will be also avoided.
\end{abstract}

Keywords Compacted soils $\cdot$ Laboratory tests $\cdot$ Cover system $\cdot$ Design $\cdot$ Construction $\cdot$ Control

\section{Introduction}

Mineral barriers of municipal solid waste (MSW) landfills extend on very large areas, in the order of tens of hectares. According to national standards [1], mineral barriers must have a minimum thickness of $0.5 \mathrm{~m}$ and a maximum hydraulic conductivity of $10^{-8} \mathrm{~m} / \mathrm{s}$. The latter is a difficult standard to achieve in the field because of the construction procedure and the very high compressibility of the below wastes.

In situ permeability tests, as Boutwell permeameter [2], lysimeter [3] or sealed double-ring infiltrometer [4], are generally not performed in adequate numbers due to their experimental difficulty and costs, correlated to the mineral liner damage and subsequently functional repairs. Engineers tend to rely on in situ density tests to check indirectly the barrier permeability. The water content and dry density are checked, while the hydraulic conductivity is estimated using laboratory relationship with the water content. This approach assumes equal compaction energy in the field and laboratory. However, this assumption is rarely respected. Field compaction energy depends on several factors, often 
hard to control, such as compaction equipment (weight and size of the roller, vibratory frequency rate), soil properties (water content, dry density, size of clay clods) and compaction procedures (vehicle velocity, number of passes, layer thickness). Moreover, in situ compacted mineral liner is generally realised using clods of particles of different sizes and it can be less homogeneous than Proctor specimens obtained in laboratory, performed with clods completely crushed.

Lacking this energy equivalence, the comparison between laboratory and field results completely loses scientific and practical value. If the two compaction curves are not equal, different dry densities will correspond to the optimum water content $\left(w_{\text {opt }}\right)$. This will have significant effect on the hydraulic conductivity as well. Depending on the location of the data point $\left(w ; \rho_{\text {dry }}\right)$, the hydraulic conductivity may be lower or higher than the limit hydraulic conductivity set by the codes. It is evident that an in situ control, based exclusively on the determination of water content and dry density of the mineral liner, does not properly consider the effect of the compaction energy on the actual behaviour of the liner.

For these reasons, a rigorous and innovative procedure for design, construction and control of a compacted mineral liner in a capping multi-layer system was developed and presented in detailed in this paper. In particular, in the design phase a not usual procedure to analyse the compaction and permeability laboratory tests has been introduced. After defining the compacted mineral layer design parameters at laboratory scale, the achievement of design values was checked on a test field by means of in site tests. Then the construction of compacted mineral barrier was carried out according the construction procedure defined in the field test.

Finally, a not usual procedure was also suggested in order to control the compacted layer hydraulic performance. The $k$ control procedure is based on an analytical equation obtained using the not usual procedure adopted in order to analyse the laboratory tests. It allows to evaluate $k$ by means of analytical equation obtained interpreting laboratory test results in terms of degree of saturation. The equation uses only the value of $\rho_{\mathrm{d}}$ measured in site to evaluate $k$. This should allow to carry out only in site $\rho_{\mathrm{d}}$ tests and measurements of $w$ with less damage for the constructed compacted mineral barrier. The proposed method to control the hydraulic conductivity of constructed compacted layer has been validated by means of the results of a detailed experimental study carried out in site.

\section{Compacted Mineral Liner Design Procedure}

The studied landfill is a waste disposal facility for Municipal Solid Waste (MSW) located in Grumolo delle Abbadesse (Vicenza, Italy). The landfill extends for $140,000 \mathrm{~m}^{2}$ and collects waste from 45 municipalities within the Vicenza province (Fig. 1).

Landfill cover systems are composed of a set of critical and design specific layers. The compacted mineral liner, with minimum thickness of $0.5 \mathrm{~m}$ and hydraulic conductivity not greater than $10^{-8} \mathrm{~m} / \mathrm{s}$, controls barrier effects and is critical in the landfill construction given its relation to rainfall infiltration.

The soil used for the capping design of the Grumolo landfill was a silty clay derived from pit excavation. The excavated soil was then subjected to laboratory tests (e.g. grain size analysis, Atterberg limits, X-ray diffractometer, scanning electron microscopy and SEM) to assess the suitability of the soil to be used for compacted mineral liners and to define the design procedure in order to fulfil the requirements of the national regulations in terms of hydraulic conductivity (e.g. reduced, standard and modified Proctor compaction tests [5-7] and constant head permeability test in triaxial cell [8]).
Fig. 1 Grumolo delle Abbadesse landfill

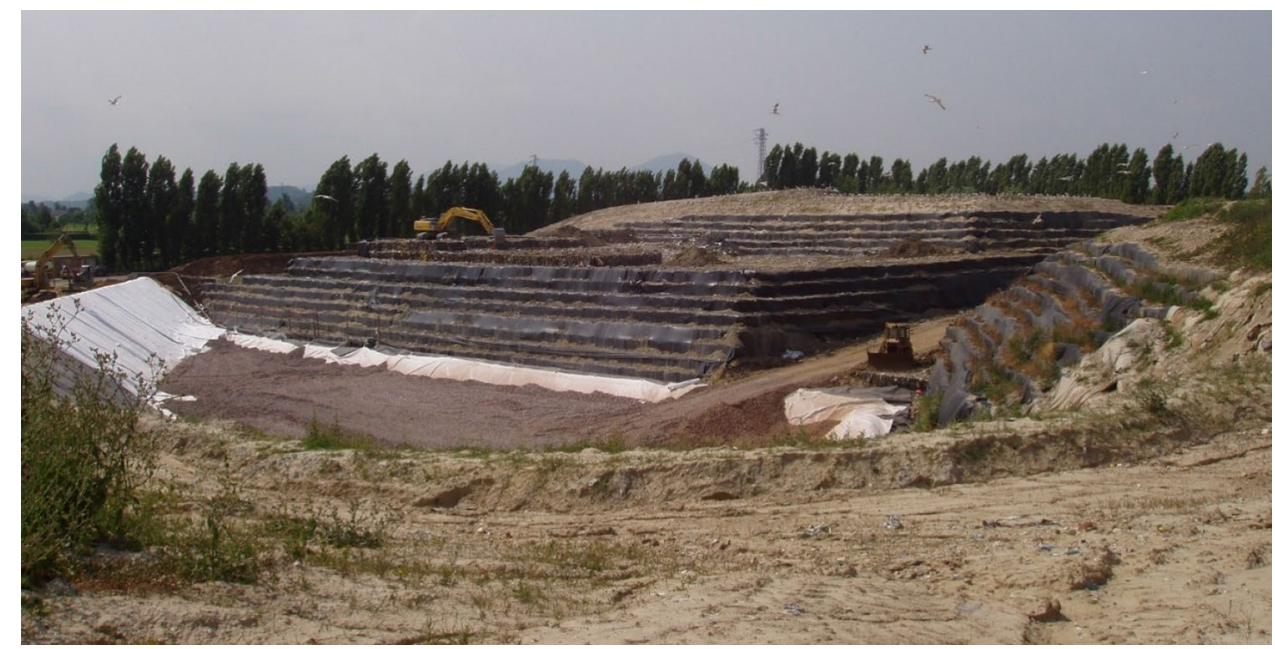


Fig. 2 Grain size distribution of the investigated soil

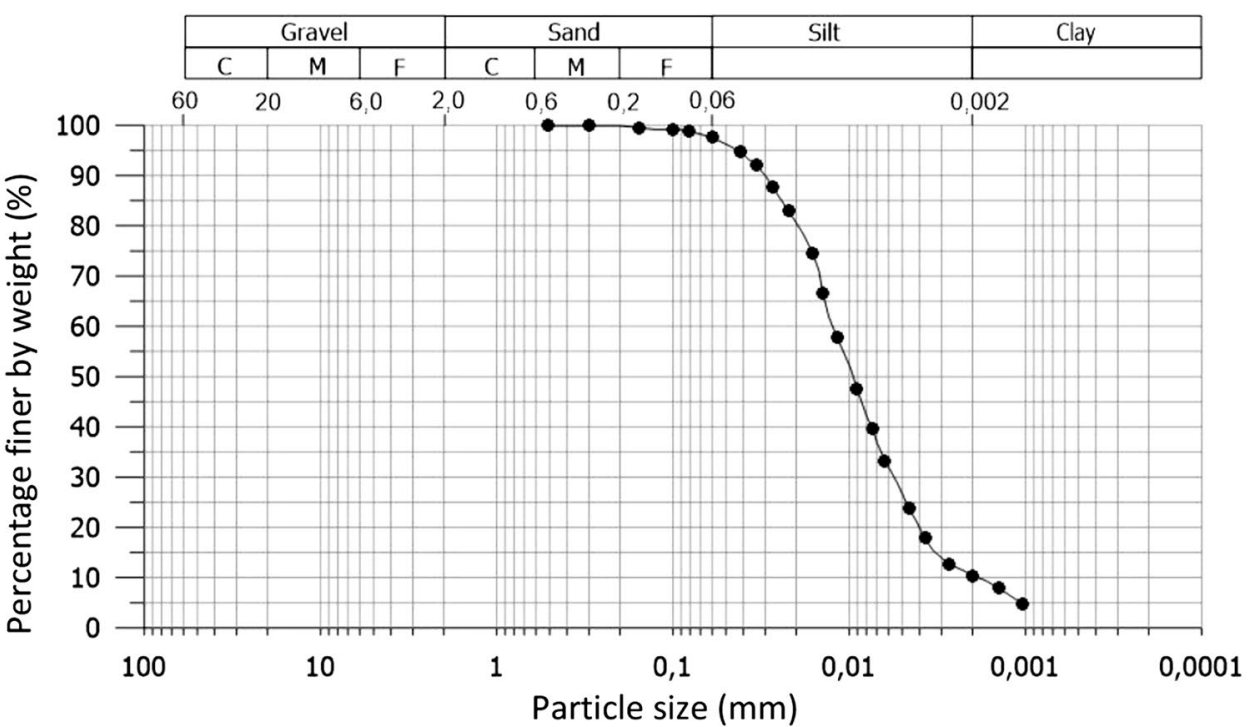

Table 1 Atterberg limits, plasticity index and specific soil weight of Grumolo soil

\begin{tabular}{ll}
\hline Liquid limit (LL) (\%) & 44 \\
Plasticity index (PI) $(\%)$ & 21 \\
Specific gravity of soil solid $\left(G_{\mathrm{s}}\right)$ & 2.76 \\
\hline
\end{tabular}

Table 2 Geotechnical properties of Grumolo soil

\begin{tabular}{lll}
\hline Geotechnical properties & Test soil & Italian guidelines \\
\hline Passing sieve $0.075 \mathrm{~mm}(\%)$ & 98 & $\geq 25$ \\
Plasticity index (\%) & $18 \div 22$ & $10 \div 50$ \\
Gravel percentage (\%) & 0 & $\leq 40 \%$ \\
Maximum grain size (mm) & 0.4 & $\leq 25$ \\
\hline
\end{tabular}

The design process is divided in three phases: material selection, laboratory tests and construction of the test site field.

\section{Material Choice}

The soil was selected through grain size analysis [9] (Fig. 2) and Atterberg limits [10] (Table 1). The test soil was classified according to the USCS [11] as an inorganic clay of medium plasticity (CL). Medium plasticity implies ductility, workability and self-healing capability against high differential settlements of the waste, which can produce cracks in the barrier, increasing its hydraulic conductivity.

Additional geotechnical aspects [12] must be considered to achieve hydraulic conductivity less than $10^{-8} \mathrm{~m} / \mathrm{s}$, as shown in Table 2. A comparison with the experimental values shows the test soil is suitable as a mineral barrier for the Grumolo cover system.



Fig. 3 Compaction curves for the Grumolo soil at reduced $(0.5 \mathrm{Ec})$, standard $(1.0 \mathrm{Ec})$ and modified $(4.5 \mathrm{Ec})$ compaction energies. Coloured region indicates optimum water content range

\section{Laboratory Tests to Evaluate Design Parameters of Compacted Liner}

After material selection, laboratory compaction and permeability tests were performed to verify if the selected soil matched the national regulation requirements, when compacted at different energy levels.

Compaction tests were carried out at three compaction energies: modified 4.5Ec [7], standard 1.0Ec [6] and reduced $0.5 \mathrm{Ec}[5]$.

Figure 3 shows the results of the Proctor compaction tests for different energy levels $(\mathrm{Ec})$. These results resemble the typical shape of compaction curves for silty-clay soils with the optimum water content ( $w_{\text {opt }}$ or OWC) ranging from $15.6 \%$ (modified energy) to $23.2 \%$ (reduced energy). No single optimum water content can be identified for all compaction energies. However, the compaction curves at different 
energies are very similar to each other and the optimum line aligns almost parallel to the $100 \%$ saturation curve, shifting to the top-left for higher compaction energies. The pairs of maximum dry density and optimum water content $\left(\rho_{\mathrm{d}, \max }\right.$; $w_{\text {opt }}$ ) obtained for all the Proctor compaction energies are listed in Table 3.

Constant head permeability tests were carried out on specimens compacted at standard and reduced energy levels using a hydraulic gradient of 30 in triaxial cell [8]. Modified-energy-compacted specimens were not considered for the permeability tests, because the compaction energies used for the final cover system of MSW landfills range between standard and reduced due to the high waste compressibility.

Figure 4 shows the trends of hydraulic conductivity with water content at these two compaction energies. Experimental values were always below the limit imposed by Italian regulation. The test soil compacted at the two different energies was considered suitable to be used as barrier in the cover system of a MSW landfill.

All pairs $w-\rho_{\mathrm{d}}$ guarantee a suitable hydraulic conductivity both in the dry and wet zones (Fig. 4). The field test was realised using a water content ranging from 21 to $23.5 \%$, which represent the OWC values for standard and reduced compaction energies.

The laboratory permeability values represent a minimum threshold of the values which were to be achieved on site. This is because the mixing and compaction techniques used in the laboratory are more accurate than those used on site. Mixing procedures for dry and powdered soils are very simple in the laboratory, but they are more complicated in situ where soil is wet and contains clods.

\section{Interpretation of Laboratory Tests in Terms of Degree of Saturation}

The compaction data were analysed expressing the water content in terms of the degree of saturation. A set of similar compaction curves on the $\left(S_{\mathrm{r}}-\rho_{\mathrm{d}}\right)$ plot was obtained (Fig. 5). Such curves show a vertical shift due to the variation of compaction energy, but they reach their maximum at approximately the same degree of saturation, $S_{\text {ropt }}(\sim 83 \%)$, which is independent of the applied compaction energy.

The previous data were then analysed by normalisation with respect to the optimum degree of saturation $\left(S_{\mathrm{r}}-S_{\mathrm{r}, \mathrm{opt}}\right)$

Table 3 Pairs of values $\left(\rho_{\mathrm{d} \text {,max }}, w_{\text {opt }}\right)$ of test soil at reduced, standard and modified Proctor compaction energies

\begin{tabular}{lll}
\hline & $\rho_{\mathrm{d}, \max }\left(\mathrm{Mg} / \mathrm{m}^{3}\right)$ & $\mathrm{w}_{\mathrm{opt}}(\%)$ \\
\hline Reduced proctor energy & 1.57 & 23.0 \\
Standard proctor energy & 1.63 & 21.0 \\
Modified proctor energy & 1.80 & 15.6 \\
\hline
\end{tabular}

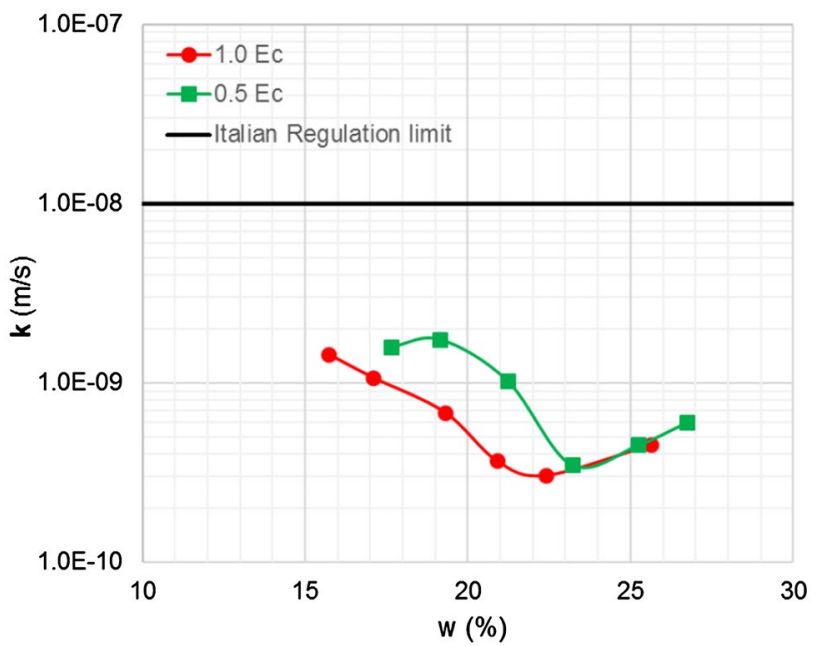

Fig. 4 Constant-head permeability tests on $0.5 \mathrm{Ec}$ and $1.0 \mathrm{Ec}$ compacted specimens

and the respective maximum dry density $\left(\rho_{\mathrm{d}} \rho_{\mathrm{d}, \max }\right)$ for each compaction energy (Fig. 6) according to the approach proposed by others researchers $[13,14]$. Normalised compaction curves are approximately equivalent independently of compaction energy. The standard deviation of the data points of different compaction energy is minimised at the proximity of $S_{\text {ropt }}$.

As a result, the analysis of the degree of saturation makes possible to know the compaction conditions (i.e. dry or wet of optimum), without the need of knowing the in situ compaction energy.

Figure 7 presents the data from the constant head permeability tests in terms of water content, dry density and degree of saturation for the reduced and standard energy compacted specimens. The results show two distinct data groups on two straight lines with similar slopes. Each

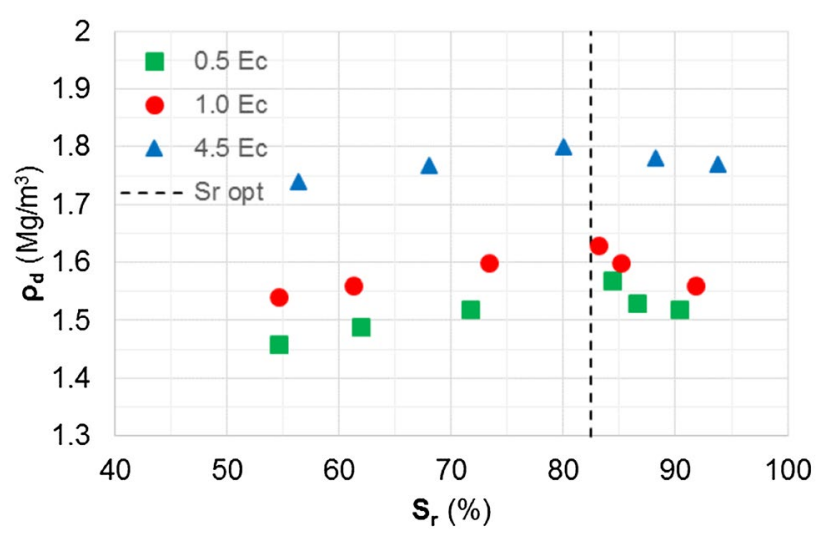

Fig. 5 Compaction curves on $\left(S_{\mathrm{r}}-\rho_{\mathrm{d}}\right)$ plot for the Grumolo soil for the three different compaction energies 


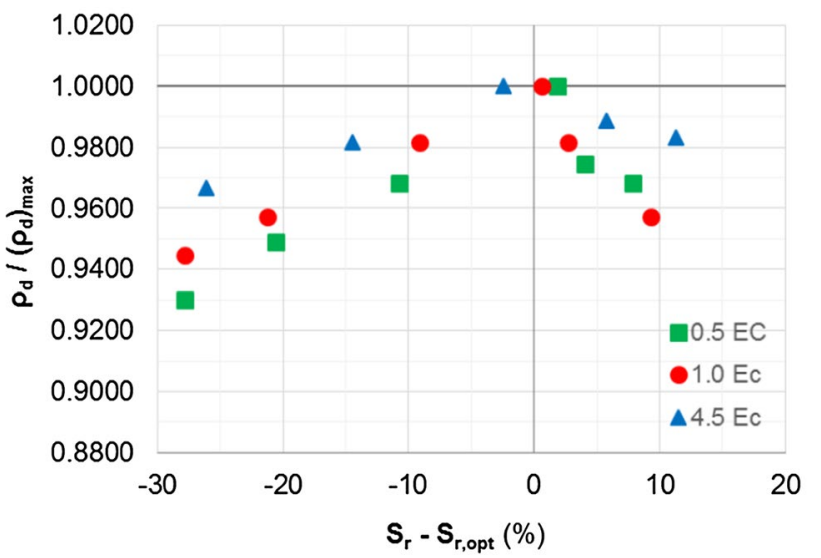

Fig. 6 Normalised compaction curves on $S_{\mathrm{r}}-S_{\mathrm{r}, \mathrm{opt}}$ vs. $\rho_{\mathrm{d}} /\left(\rho_{\mathrm{d}}\right)_{\max }$

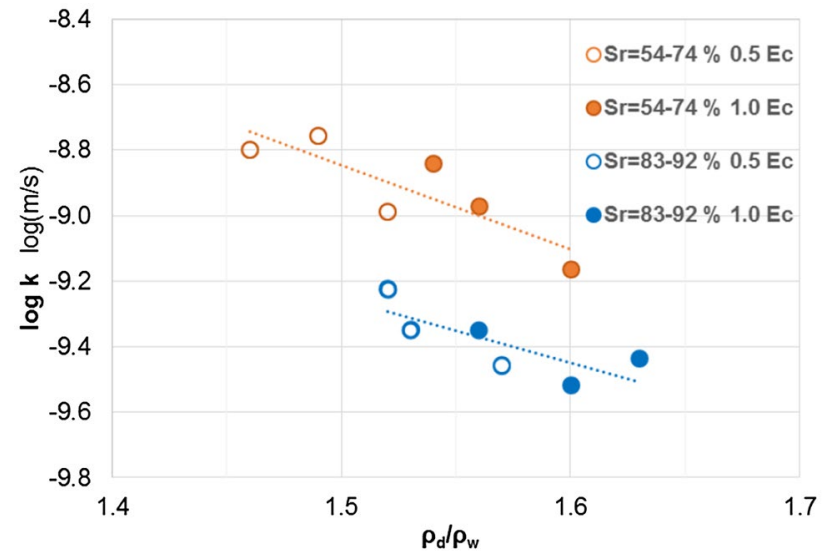

Fig. $7 \rho_{\mathrm{d}} / \rho_{\mathrm{w}}-\log (k)$ plot for different $S_{\mathrm{r}}$ and energy levels

group corresponds to a particular range of degree of saturation: $S_{\mathrm{r}}=54 \div 74 \%$ is related to dry compaction conditions; $S_{\mathrm{r}}=83 \div 92 \%$ is representative of compaction at optimum and wet conditions.

The average hydraulic conductivity is unique between the two data groups and independent of the compaction energy, meaning that the compaction effort does not influence such trend. On the contrary, the effect of the degree of saturation is evident, with lower permeability reached at degree of saturation ranging from 83 to $92 \%$. By shifting the control variable to the degree of saturation, the energy dependence is removed altogether from the problem.

Since the fitted lines at the two saturation ranges have very similar slopes, it is possible to determine the value of slope $(\alpha)$ of each straight line. This value for Grumolo soil is equal to 2.26 (Fig. 7).

Using the approach proposed by Tatsuoka [13], the equation to evaluate the hydraulic conductivity can be expressed, as follows: $\log k=\alpha\left[\rho_{\mathrm{d}, \max , 1 \mathrm{Ec}}-\rho_{\mathrm{d}}\right] / \rho_{\mathrm{w}}+\log f_{\mathrm{k}}\left(S_{\mathrm{r}}\right)$

$f_{\mathrm{k}}\left(S_{\mathrm{r}}\right)=\frac{k}{10^{\alpha\left[\rho_{\mathrm{d}, \max , 1 \mathrm{Ec}}-\rho_{\mathrm{d}}\right] / \rho_{\mathrm{w}}}}$.

Looking at the laboratory experimental data, the function $\log f_{\mathrm{k}}\left(S_{\mathrm{r}}\right)$ shows a single trend for all the compaction energies with a rapid decrease after reaching a $S_{\mathrm{r}}$ threshold of approximately $65 \div 70 \%$ (Fig. 8 ). The data corresponding to the optimal compaction $\left(w_{\text {opt }}\right)$ fall very close to each other in the proximity of $S_{\mathrm{r}, \mathrm{opt}}$, independently of the compaction energy.

For the compacted Grumolo soil, the Eq. (1) is characterised by:

- $\alpha$ equal to 2.26 ;

- $\rho_{\mathrm{d}, \max , 1 \mathrm{Ec}}$ equal to $1.63\left(\mathrm{Mg} / \mathrm{m}^{3}\right)$, maximum compaction measured through laboratory tests at standard Proctor energy;

- $\rho_{\mathrm{w}}$ water density, considered equal to $1.0\left(\mathrm{Mg} / \mathrm{m}^{3}\right)$;

- $\rho_{\mathrm{d}}$ in situ measured dry density $\left(\mathrm{Mg} / \mathrm{m}^{3}\right)$.

Therefore, Eq. 1 becomes:

$\log k=2.26\left[1.63-\rho_{\mathrm{d}}\right] / 1+\log f_{\mathrm{k}}\left(S_{\mathrm{r}}\right)$.

Assuming a single value of the parameter $f_{\mathrm{k}}\left(S_{\mathrm{r}}\right)$ equal to $3.68 \times 10^{-10}(\mathrm{~m} / \mathrm{s})$, evaluated at optimum compaction conditions at the reference compaction energy, an analytical relationship between $k$ and in situ dry density in the range of optimum degree of saturation (alternatively, optimum compaction) can be determined.

$k=3.68 \times 10^{-10} \times 10^{2.26\left[(1.63)-\rho_{\mathrm{d}}\right] / 1}$.

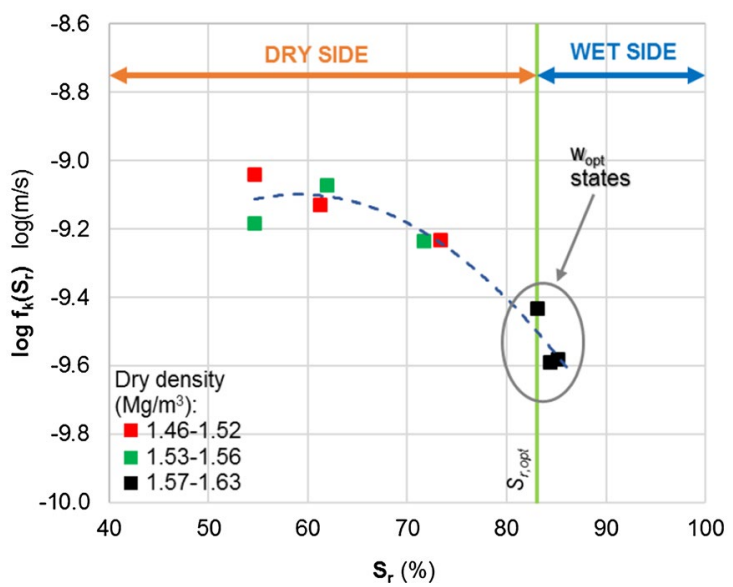

Fig. $8 S_{\mathrm{r}}-\log f_{\mathrm{k}}\left(S_{\mathrm{r}}\right)$ curve for Grumolo soil 


\section{Realization of Field Test Site}

A field test site was built to define the construction procedure in order to obtain the desired design parameters (e.g. water content, dry density and hydraulic conductivity).

Considering the values of OWC obtained in laboratory using the different energies (21\% for standard energy and $23 \%$ for reduced energy) and the related laboratory permeability, water contents for field test ranging from 22 to $23.5 \%$ have been adopted.

Moreover, in order to reach the desired compaction energy, a not usual compaction equipment was used. In this case, a dumper was considered suitable to compact the mineral soil in the test field (Fig. 9) instead of heavy sheep foot rollers generally used to compact clayey soils.

The testing site $(40 \mathrm{~m} \times 20 \mathrm{~m})$ was constructed on top of the landfill body in place of the final cover to test the field compaction procedure and to control the in situ hydraulic conductivity of the mineral liner [15]. Construction of the test site and in situ tests were carried as follows:

- Step 1: temporary removal of cover;

- Step 2: excavation of soil to be used in the mineral barrier;

- Step 3: determination of the natural soil water content;

- Step 4: preparation of backfill material for the testing site at the desired water content range between $21 \div 23 \%$, as considered in the laboratory tests. The field water content was greater than the design water content; therefore, the natural soil was left to dry under the effect of favourable weather conditions for two weeks. Numerous tests were performed at different depths to ensure that the water content was as homogenous as possible within the soil mass and within the desired limits;

- Step 5: disintegration of big-sized clay clods;
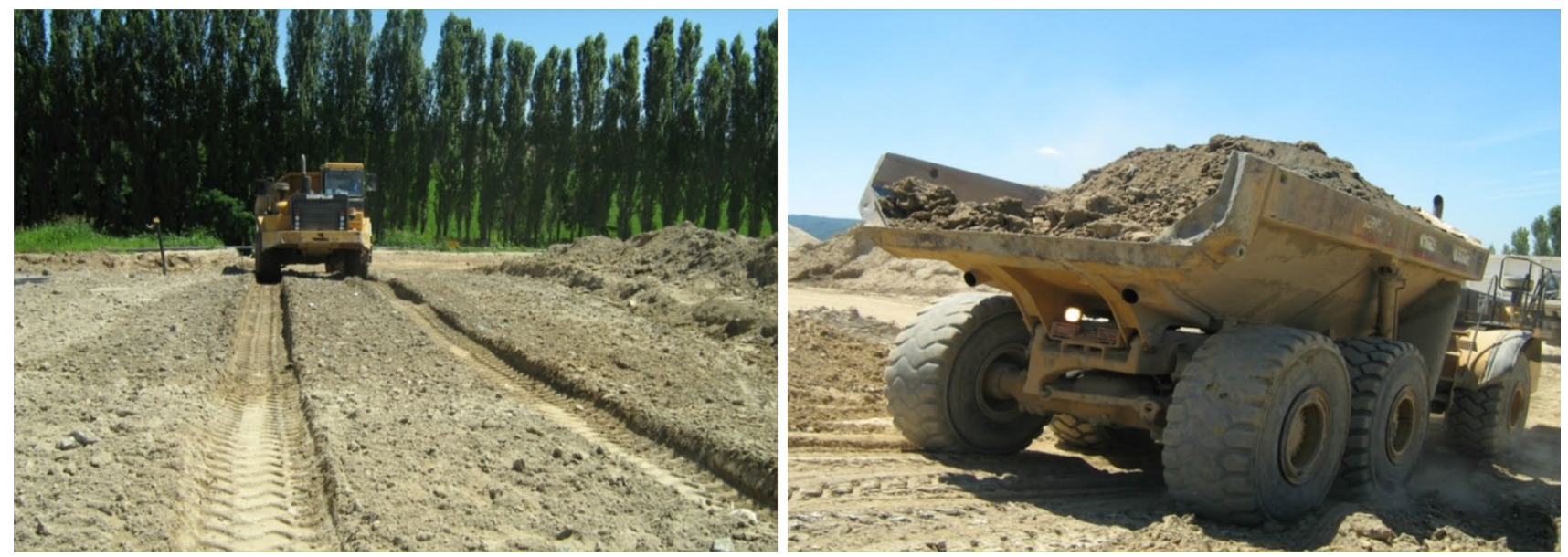

Table 4 Sand cone tests results

\begin{tabular}{llllll}
\hline $\begin{array}{l}\text { Com- } \\
\text { paction } \\
\text { energy }\end{array}$ & $\begin{array}{l}\rho_{\mathrm{d} \text { max }}(\mathrm{Mg} / \\
\left.\mathrm{m}^{3}\right)\end{array}$ & $\begin{array}{l}\text { Num- } \\
\text { ber of } \\
\text { passes }\end{array}$ & $\begin{array}{l}\text { Dumper } \\
\text { weight } \\
(\mathrm{kN})]\end{array}$ & $\begin{array}{l}\rho_{\mathrm{d}, \mathrm{situ}}(\mathrm{Mg} / \\
\left.\mathrm{m}^{3}\right)\end{array}$ & $\mathrm{DC}(\%)$ \\
\hline $0.5 \mathrm{Ec}$ & 1.57 & 4 & 400 & 1.55 & 98.7 \\
$1.0 \mathrm{Ec}$ & 1.63 & 4 & 450 & 1.55 & 95.1 \\
\hline
\end{tabular}
ficult because of the compressible subbase, especially when soil water content is $3 \%$ greater than the optimum water content. In addition, the dumper wheels' furrows can be quite deep (up to $0.15 \mathrm{~m}$ from the ground level) and require a suitable levelling to allow the successive layers to be placed and compacted.

In situ density tests were performed through the sand cone test apparatus and showed that the compaction energy due to the dumper depended on its variable static weight and on the number of passes (Table 4).

For optimal cover operations, the dumper load was 450 $\mathrm{kN}$. However, this load had to be sometimes limited to avoid the damage of mineral barrier's components, such as geocomposites. Upon increasing the load in the rear compartment of the dumper, the degree of compaction corresponding to the reduced and standard Proctor energies could be achieved without varying the number of passes. Using four

Fig. 9 Compaction of liner by dumper 
passes and an OWC equal to $23 \%$, a $400 \mathrm{kN}$ and a $450 \mathrm{kN}$ dumper weights can be used to achieve a degree of compaction $\left(\mathrm{DC}=\rho_{\mathrm{d}, \mathrm{situ}} / \rho_{\mathrm{d}, \max } \times 100\right)$ equal to the $98.7 \%$ and $95.1 \%$ of the optimum compaction obtained with reduced and standard Proctor energy, respectively. The test results highlighted the importance of the driver training. Workers, who were familiar with the dumper and quickly acquired the expertise to use it for this new finality, performed a compaction characterised by the good spatial homogeneity of the mineral barrier properties.

A further important aspect in the mineral liner design was to assess the in situ hydraulic conductivity and to compare it with the laboratory values using reduced and standard Proctor energies at various water content. For this purpose, different sections of field test were constructed using initial water contents ranging from 22 to $23.5 \%$.

The results of in situ permeability tests were obtained using Boutwell permeameter, which is considered one of the most suitable instruments to assess the hydraulic conductivity of a compacted soil. The test results refer to an in situ degree of compaction equal to the $95.1 \%$ of the optimum compaction obtained in the laboratory with standard Proctor energy. The experimental values of hydraulic conductivity were always less than $10^{-8} \mathrm{~m} / \mathrm{s}$, as required by the national regulations. The hydraulic conductivity decreases with the increase of water content and then it becomes steady for $\mathrm{w}$ greater than $22.5 \%$, as shown in Table 5. This trend is very similar to the one obtained with laboratory tests (Fig. 4). The accuracy of the in situ evaluations seems to be very similar to that obtained in laboratory.

\section{In Situ Control Tests of Design Parameters of Compacted Mineral Barrier}

The compacted mineral barrier was realised using the procedure stated in the previous step (test field). The excavated soil was used to construct the mineral barrier. In particular, on the base of laboratory and field test results, it was decided to construct the actual cover system mineral barrier at a design water content around 23\%, using a dumper of $450 \mathrm{kN}$ adopting for each layer at least four passes.

The in situ compaction control is commonly based on the check of $\rho_{\mathrm{d}} w$ and $k$. In this case, sand-cone method tests, water content measurements and permeability tests were carried out.

The most important geotechnical parameter for compacted clay in landfills is the hydraulic conductivity because

Table 5 Results of Boutwell tests it controls the barrier efficiency. It is very important to perform field permeability tests to check the real value obtained in situ by the compaction. Among the many different in situ permeability tests, the Boutwell [2] permeability tests were used to evaluate the permeability of the Grumolo cover system mineral barrier.

The in situ compaction of the soil liner was carried out by hydrating the soil to a water content slightly higher than its OWC (Standard Proctor, 1.0Ec) between 21 and 24\%.

The dry densities obtained during compaction in the field range between 1.50 and $1.55 \mathrm{Mg} / \mathrm{m}^{3}$, with measured water content varying from 21 to $24 \%$. These dry density data show that compaction at standard energy was not reached (Fig. 10). However, the compaction project requirements were still met, as the degree of compaction DC at the Grumolo testing site ranges between 92 and $95 \%$.

The data are in according with a dry of optimum compaction, with some samples corresponding to energy levels lower than $0.5 \mathrm{Ec}$ and a few others to energies in between the reduced and the standard one (Fig. 10). Moreover, the degree of compaction DC for the Standard Proctor (1Ec) of the actual liner varied from 90 to $95 \%$.

\section{Proposed Check Procedure and Validation}

The liner control focused on the degree of saturation and dry density. The data obtained on specimens taken on the real compacted liner show that the degree of saturation corresponding to each $\left(w, \rho_{\mathrm{d}}\right)$ pair never reaches the optimum value (Fig. 11). According to these results, it is apparent that field compaction had actually taken place in the dry of optimum conditions, corresponding to negative values on the $x$ axis of the normalised plot (Fig. 11) independently of the real compaction energy, whose actual value is unknown.

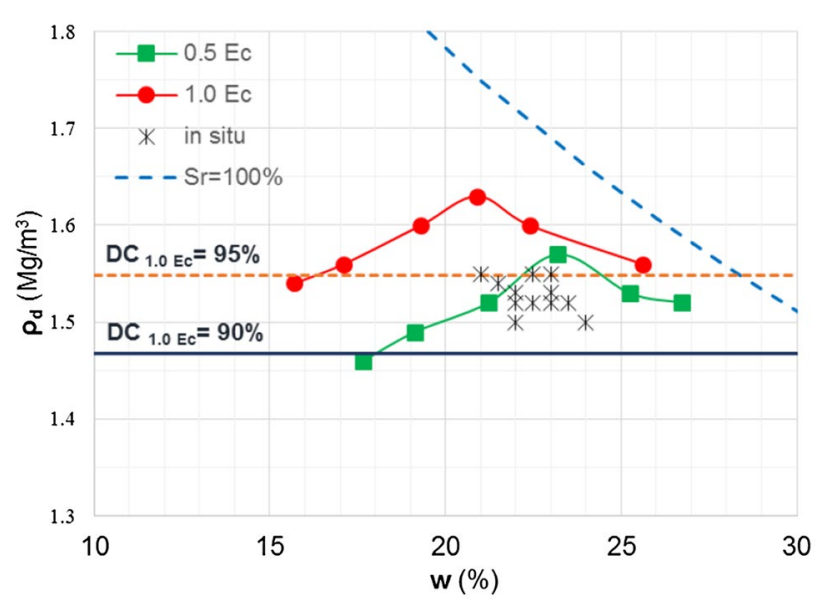

Fig. 10 In situ density tests compared with compaction curves for 0.5 $\mathrm{Ec}$ and $1.0 \mathrm{Ec}$ and degree of compaction requirement 


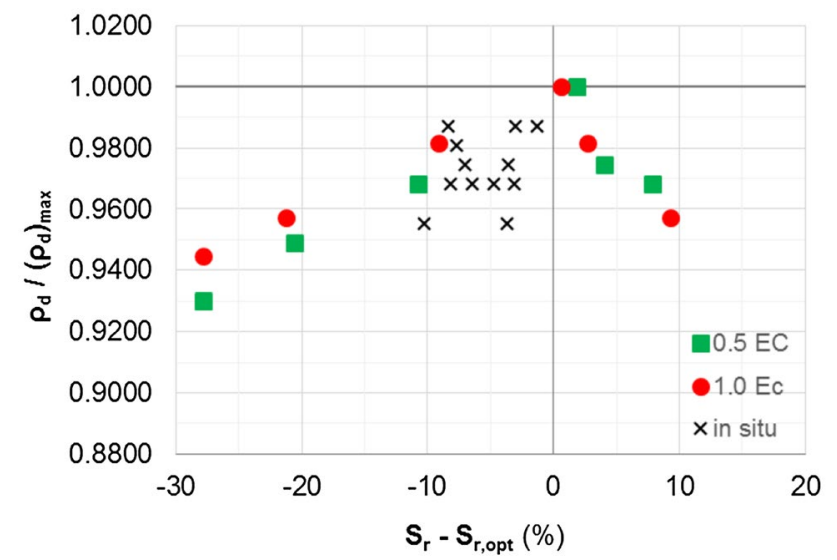

Fig. 11 In situ dry density results on the $S_{\mathrm{r}}-S_{\mathrm{r} \text {,opt }}$ vs. $\rho_{\mathrm{d}} /\left(\rho_{\mathrm{d}}\right)_{\max }$ plot

In order to overcome the dependence on compaction energy, $k$ had been evaluated by means of Eq. (3) based on laboratory test results for the Grumolo soil, using $\rho_{\mathrm{d}}$ values obtained by in situ determinations. The predicted values were then compared to test results and laboratory tests.

The predicted values of $k$, obtained analytically through Eq. (3), are always greater than the minimum coefficients $k$ corresponding to the standard Proctor energy (1.0Ec), but still comply with the Italian law requirement for mineral barrier of cover system.

In order to carry out a further check of the liner permeability a small portion of the compacted mineral liner was made $1 \mathrm{~m}$ thick and a new set of two stage borehole (TSB) [2, 17-19] was performed with Boutwell permeameter (Fig. 12).

Both of the results of the TSB tests (Table 5) and the hydraulic conductivity $k$ values as a function of the dry density the degree of saturation of the actual liner predicted by Eq. (3) are plotted in Fig. 13. It may be seen that, although the field test results exhibit relatively large scatter, they are generally consistent with the predicted hydraulic conductivity $k$ values. The higher hydraulic conductivity values in the

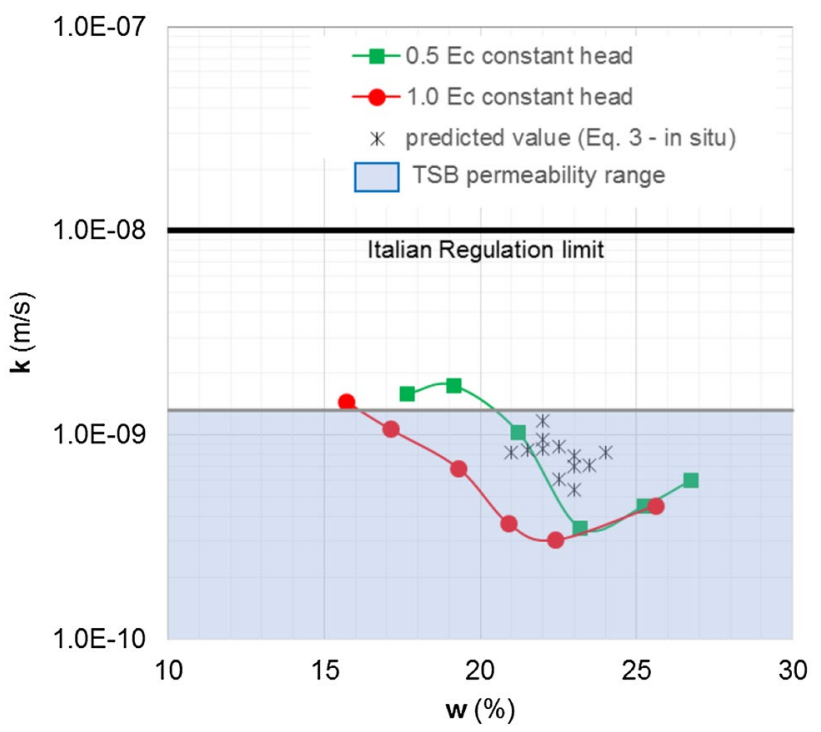

Fig. 13 Comparison of TSB test results with laboratory tests and predicted hydraulic conductivity values

field are probably due to the influence of the macro-structure of the compacted clay liner, as laboratory tests cannot reproduce the effect of bigger clay clods in the silty matrix of the soil, nor the difficulties of the field compaction procedures, resulting in variations of the compaction energies.

No exact correspondence between laboratory and in situ tests can be reasonably expected. The comparison between predicted $k$ values (function of $\rho_{\mathrm{d}, \mathrm{situ}}$ and $S_{\mathrm{r} \text {,situ }}$ through Eq. 3) and the field range of $k$ can give a good estimate of real in situ conditions and, most importantly, hydraulic conductivity control through the use of the degree of saturation seems to be a very reliable choice.

By establishing an acceptable degree of saturation range, it can expect that in situ hydraulic conductivity will fall within the desired range, no matter the compaction energy according to Tatsuoka [13] and Tatsuoka and Correia [14].
Fig. 12 Boutwell permeameter tests
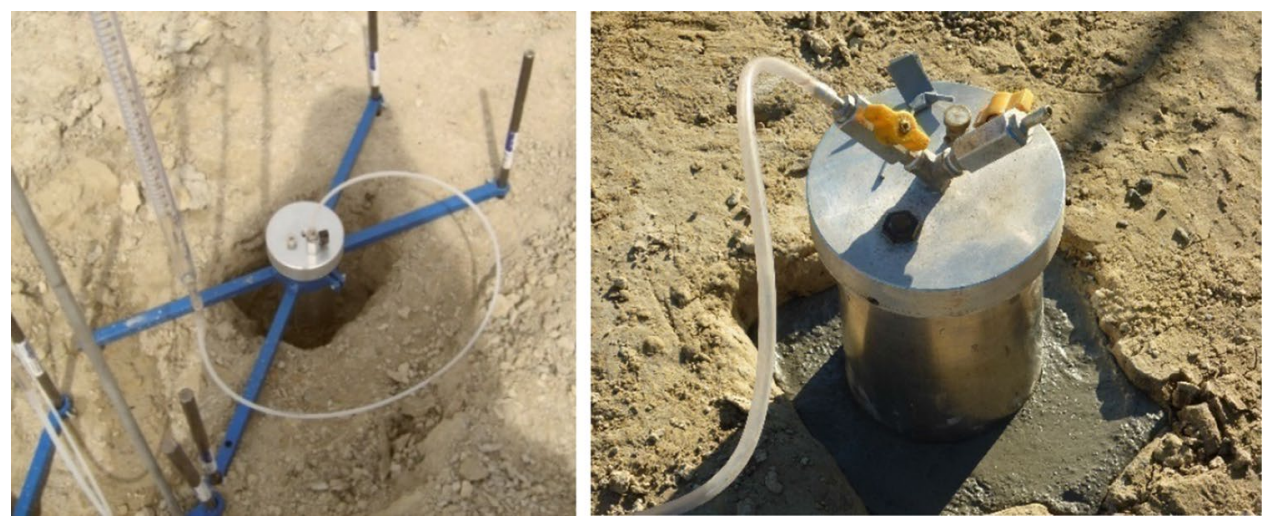
Table 6 Flow chart proposed to design in detail a mineral liner of a cover system

\begin{tabular}{|c|c|c|}
\hline Phase & Action & Methodology/outcomes \\
\hline \multicolumn{3}{|l|}{ Design } \\
\hline I step & Material choice & Classification tests \\
\hline II step & $\begin{array}{l}\text { Determination of the pairs }\left(w, \rho_{\mathrm{d}}\right) \text { at different compaction } \\
\text { energies }(\mathrm{Ec}) \text {, for which the values of } \mathrm{k} \text { are less than the } \\
\text { limit value of local regulation }\end{array}$ & $\begin{array}{l}\text { Laboratory tests (compaction and permeability tests) and inter- } \\
\text { pretation of laboratory test results to obtain the equation of } \mathrm{k} \\
\text { function of } S_{\mathrm{r}} \text { and } \rho_{\mathrm{d}} \text { for the specific compacted soil }\end{array}$ \\
\hline III step & $\begin{array}{l}\text { Statement of the construction procedure (pass number, clod } \\
\text { size, layer number, etc....) that provides suitable values of } \\
w-\rho_{\mathrm{d}} \text { and } k\end{array}$ & $\begin{array}{l}\text { Realization of field test to determination of } w, \rho_{\mathrm{d}} \text { and } k \text { by } \\
\text { in situ tests }\end{array}$ \\
\hline Construction & $\begin{array}{l}\text { Construction of compacted mineral barrier according to previ- } \\
\text { ous defined procedure (III step) }\end{array}$ & $\begin{array}{l}\text { Construction supervision-verification of compliance with the } \\
\text { construction methodology }\end{array}$ \\
\hline On site control & On site check tests of the design parameters & $\begin{array}{l}\text { On site check tests of } w, S_{\mathrm{r}} \text { and }\left(\rho_{\mathrm{d}}\right)_{\mathrm{design}} \text { and evaluation of } k \text { by } \\
\text { means of the equation determined in the design phase }\end{array}$ \\
\hline
\end{tabular}

Based on the results of this research a flow chart for the design of the liners on capping is proposed (Table 6).

\section{Conclusive Remarks}

The mineral barriers of MSW landfills extend on very large areas, even tens of hectares. They must have a minimum thickness, easy to control and a hydraulic conductivity no greater than a specific value, set by the national standard. In-site permeability tests are generally not performed in adequate numbers due to their experimental difficulty and time consuming. For all these reasons, checks on the barrier hydraulic conductivity $k$ are generally based on the results of in-site density tests and on their comparison with those provided by preliminary laboratory tests. This comparison is based on the equivalence, almost never respected, between the compaction energies used in-site and in laboratory. Lacking this equivalence, the comparison completely loses scientific and practical value. For these reasons, a rigorous procedure for design, construction and control of a compacted mineral liner in a capping multi-layer system has been developed and proposed in this paper. Such a procedure may be schematically subdivided in three phases.

1. The design phase is based on a wide preliminary campaign of laboratory tests, composed of classification, compaction and permeability tests. First of all the suitability of the selected soil has to be evaluated: in particular the hydraulic conductivity $k$ of specimens, having pairs of $\left(w, \rho_{\mathrm{d}}\right)$ determined at different compaction energies $(\mathrm{Ec})$, is determined and compared to the maximum $k$ defined by the current national regulation. In order to make the results of the Proctor and permeability tests independent on the compaction energy, the experimental data are analysed in terms of degree of saturation $S_{\mathrm{r}}$ and dry density $\rho_{\mathrm{d}}$, obtaining an analytical relationship among $S_{\mathrm{r}}, \rho_{\mathrm{d}}$ and $k$. This first phase may be concluded constructing a real size mineral liner. In this way the construction procedure, evaluating the effects of the pass number, clods size, number of compacted layers etc., may be fully defined to obtain an actual mineral barrier well compacted and characterised by a hydraulic conductivity $k$ not greater than the limit requested by the specific national regulation.

2. The construction phase is developed through the compaction of the mineral barrier according to the results obtained during the previous design phase.

3. The in situ control phase consists of the determination of the design parameters $\left(w, S_{\mathrm{r}}, \rho_{\mathrm{d}}, k\right)$. To interpreting suitably these experimental data, it is possible at the same time to know the actual compaction level and its exact location (dry- or wet-side or OWC) on the compaction curve $\left(w-\rho_{\mathrm{d}}\right)$ and to check the liner hydraulic conductivity by means of the analytical relationship between the coefficient $k$ and the other mentioned parameters $\left(S_{\mathrm{r}}, \rho_{\mathrm{d}}\right)$ obtained in the design phase. Moreover, using the proposed approach there will be no longer a need for several in-site permeability tests, which also damage portions of barriers difficult to repair after the test.

4. Finally, the development of innovative mineral liner control procedures can therefore ensure the quality of the barrier through a greater number of tests, with higher reliability, easier execution and lower time consuming.

Acknowledgements The Authors are grateful to Dario Vianello (General Director of A.I.M. Group and CEO of S.I.A. Società Intercomunale Ambiente S.r.l., Grumolo delle Abbadesse, Vicenza, Italy) and Ruggero Casolin (Director of Valore Ambiente S.r.l I.M. group, Vicenza, Italy). Thanks to Geoplanning Servizi per il Territorio s.r.l. of Rome for having cooperated during the Boutwell tests execution. The authors have given the same contribution to this paper. 
Funding Open access funding provided by Università degli Studi Mediterranea di Reggio Calabria within the CRUI-CARE Agreement.

Open Access This article is licensed under a Creative Commons Attribution 4.0 International License, which permits use, sharing, adaptation, distribution and reproduction in any medium or format, as long as you give appropriate credit to the original author(s) and the source, provide a link to the Creative Commons licence, and indicate if changes were made. The images or other third party material in this article are included in the article's Creative Commons licence, unless indicated otherwise in a credit line to the material. If material is not included in the article's Creative Commons licence and your intended use is not permitted by statutory regulation or exceeds the permitted use, you will need to obtain permission directly from the copyright holder. To view a copy of this licence, visit http://creativecommons.org/licenses/by/4.0/.

\section{References}

1. Ministry of environmental and protection of land and sea (2003) Attuazione della direttiva 1999/31/CE relativa alle discariche di rifiuti. Legislative Decree 36 (in Italian)

2. ASTM D 6391-11. Standard test method for field measurement of hydraulic conductivity using borehole infiltration

3. Everett L, McMillion L, Eccles L (1988) Suction lysimeter operation at hazardous waste sites. In: Collins A, Johnson A (eds) STP963-EB ground-water contamination: field methods. ASTM International, West Conshohocken, pp 304-327. https://doi. org/10.1520/STP44868S

4. ASTM D5093-15e1 (2015) Standard test method for field measurement of infiltration rate using double-ring infiltrometer with sealed-inner ring. ASTM International, West Conshohocken. www.astm.org

5. Daniel DE, Benson CH (1990) Water content-density criteria for compacted soil liners. J Geotech Eng 116(12):1811-1830

6. ASTM D698-12. Standard test methods for laboratory compaction characteristics of soil using standard effort

7. ASTM D1557-12e1. Standard test methods for laboratory compaction characteristics of soil using modified effort

8. ASTM D5084-16a. Standard test methods for measurement of hydraulic conductivity of saturated porous materials using a flexible wall permeameter
9. ASTM D6913/D6913M-17. Standard test methods for particlesize distribution (gradation) of soils using sieve analysis

10. ASTM D4318-17e1. Standard test methods for liquid limit, plastic limit, and plasticity index of soils

11. ASTM D2487-17. Standard practice for classification of soils for engineering purposes (unified soil classification system)

12. Italian Technical Committee for Landfills (1997) Linee guida per le discariche controllate di rifiuti solidi urbani, 1st edn. CISA Centro Ingegneria Sanitaria Ambientale, Cagliari ((in Italian))

13. Tatsuoka F (2015) Compaction characteristics and physical properties of compacted soil controlled by the degree of saturation. In: Keynote lecture, deformation characteristics of geomaterials, Proc. of 6th international conference on deformation characteristics of geomaterials, Buenos Aires, pp 40-78

14. Tatsuoka F, Gomes Correia A (2018) Importance of controlling the degree of saturation in soil compaction linked to soil structure design. Transport Geotech 17:3-27

15. Moraci N, Busana S, Cortellazzo G, Favaretti M, Mandaglio MC, Schepis M (2018) Design and construction of a compacted clay liner in cover system of a municipal solid waste (MSW) landfill using nonstandard procedures. Can Geotech J 55(8):1182-1192

16. ASTM D1556/D1556M-15e1. Standard test method for density and unit weight of soil in place by the sand cone method

17. Boutwell GP (1992) The STEI two-stage borehole field permeability test. Geotechnical Committee Houston Branch, ASCE: Containment liner Technology and Subtitle D, Houston

18. Boutwell GP, Derick RK (1986) Groundwater protection for sanitary landfills in the saturated zone. In: Proc. NWWA waste-Tech '86, Chicago

19. Trautwein SJ, Boutwell GP (1994) In situ hydraulic conductivity tests for compacted soil liners and caps. In: Daniel DE, Trautwein SJ (eds) Hydraulic conductivity and waste contaminant transport in soil, ASTM STP 1142. American Society for testing and Materials, Philadelphia

Publisher's Note Springer Nature remains neutral with regard to jurisdictional claims in published maps and institutional affiliations. 